Supporting Information

\title{
Polyphenol Nanoparticles from Commonly Consumed Tea for Scavenging Free Radicals, Stabilizing Pickering Emulsions and Inhibiting Cancer Cells
}

Guangcan Chen, ${ }^{\mathrm{a}, \mathrm{b}}$ Zeng Yi, ${ }^{\mathrm{a}, \mathrm{b}}$ Xiangyu Chen, ${ }^{\mathrm{a}, \mathrm{b}}$ Xiaomin Ma, ${ }^{\mathrm{a}, \mathrm{b}}$ Wen Su, ${ }^{\mathrm{a}, \mathrm{b}}$ and Xudong Li *a,b

a National Engineering Research Center for Biomaterials, Sichuan University, Chengdu 610064, P. R. China.

${ }^{\mathrm{b}}$ College of Biomedical Engineering, Sichuan University, Chengdu 610064, P. R. China.

*: Corresponding author.

Xudong Li - National Engineering Research Center for Biomaterials and College of Biomedical Engineering, Sichuan University, Chengdu 610064, P. R. China; orcid.org/0000-0002-7939-5150; Phone: +86 (028) 85412102; Email: xli20004@yahoo.com 


\section{Detailed experimental methods}

Preparation of dopamine nanoparticles. Briefly, ethanol $(40 \mathrm{~mL})$ and aqua ammonia $\left(\mathrm{NH}_{3} \cdot \mathrm{H}_{2} \mathrm{O}\right)$ $(37 \%)(2 \mathrm{~mL})$ were mixed with water $(90 \mathrm{~mL})$ under stir at $30^{\circ} \mathrm{C}$ for $30 \mathrm{~min}$. Then dopamine hydrochloride solution $\left(10 \mathrm{~mL}, 50 \mathrm{mg} \mathrm{mL}^{-1}\right)$ was added into the mixture solution. The formed polydopamine nanoparticles were collected by centrifugation after $24 \mathrm{~h}$. The freeze-dried polydopamine nanoparticles were re-dispersed in water with ultrasonic processing for determining the antioxidant capacity.

Determination of free radical scavenging capacity. All the radical solution should keep in dark before test, and the measurement should be carried out under dim light. DPPH was dissolved in methanol with the help of ultrasonic to prepare the DPPH radical working solution $(0.4 \mathrm{mM})$. Aqueous potassium persulfate solution $(140 \mathrm{mM}, 88 \mu \mathrm{L})$ was added into aqueous ABTS solution $(7 \mathrm{mM}, 5 \mathrm{~mL})$ to prepare the ABTS stock solution. The stock solution should age 10-16 h before use. Then the aged ABTS stock solution was diluted about 20 times with methanol where the absorbance was adjusted to $0.7 \pm 0.05$ at $734 \mathrm{~nm}(100 \mu \mathrm{L}$ of initial solution in a 96-well plate)

For free radical scavenging assay, $10 \mu \mathrm{L}$ of polyphenol nanoparticles solution and $200 \mu \mathrm{L}$ of DPPH (or ABTS) working solution were added in to the 96-well plate and mixed well. Then the 96-well plate was kept in dark for $30 \mathrm{~min}$ at $25^{\circ} \mathrm{C}$. The absorbance was measured on a microplate reader at $517 \mathrm{~nm}$ for DPPH solution and $734 \mathrm{~nm}$ for ABTS solution. The formulation below was used to calculate free radical scavenging activity.

$$
\text { Scavenging activity }=\left(1-\frac{A_{\text {Sample }}-A_{\text {control }}}{A_{0}}\right) \times 100 \%
$$

Where $A_{\text {Sample }}$ is the absorbance of DPPH (or ABTS) working solution mixed with nanoparticles after $30 \mathrm{~min}$. $A_{\text {control }}$ is the absorbance of the methanolic polyphenol nanoparticle solution and $A_{0}$ is the absorbance of initial DPPH (or ABTS) working solution.

The antioxidant capacity was quantified by the result form the ABTS radical scavenging assay, and the Trolox was introduced as a reference antioxidant. The antioxidant capacity of different material was expressed relative to Trolox for the convenient comparation. The formulation below was used to calculate the antioxidant capacity:

$$
\frac{E C_{50}(\text { Trolox })}{250.34} \times \frac{1}{E C_{50}(\text { Sample })} \times 1000=\text { Antioxidant capacity }\left(\text { mmol TE }^{-1}\right)
$$

Where 250.34 is the molecular weight of Trolox. The EC50 is the defined as the concentration (mg L-1) of the sample which scavenge 50\% ABTS radical in the test, usually calculated by the fitted line of material concentration vs. ABTS scavenging rate.

Scavenging reactive oxygen species (ROS) and nitrogen species (NOS) in cells. The intracellular NOS level was represented by the concentration of nitrite which was measure by the Griess reagent (1\% sulfanilamide, $0.1 \% \mathrm{~N}$-(1-naphthyl)-ethylene-diamine dihydrochloride with $\left.2.5 \% \mathrm{H}_{3} \mathrm{PO}_{4}\right)$. The ROS were identified by using the fluorescent probe $2^{\prime}, 7^{\prime}$ - Dichlorofluorescin diacetate diacetate (DCFH-DA) and quantified by a flow cytometer. Raw 264.7 cells were cultured in DMEM (high glucose) medium containing $10 \% \mathrm{FBS}$ and $1 \%$ penicillin-streptomycin with the atmosphere of $95 \%$ air and $5 \% \mathrm{CO}_{2}$ at 
$37^{\circ} \mathrm{C}$. For determination of nitrite, RAW 264.7 were seeded in 24 -well plates $\left(2 \times 10^{5} /\right.$ well $)$. After $12 \mathrm{~h}$, the RAW 264.7 cells were pretreated with various concentrations of polyphenol colloidal particles for $2 \mathrm{~h}$, then the cells were stimulated with LPS $\left(500 \mathrm{ng} \mathrm{mL}^{-1}\right)$ for $24 \mathrm{~h}$. 
To measure the nitrite, an equal volume $(100 \mu \mathrm{L})$ of culture medium and Griess reagent were mixed in the 96-well plate and reacted for $10 \mathrm{~min}$ at room temperature. Absorbance of the mixture was measured on a microplate reader and the concentration of nitrite was calculated by a stand curve of sodium nitrite. For determination of ROS level, RAW 264.7 were seeded in 6 -well plates $\left(1 \times 10^{6} /\right.$ well $)$. After $12 \mathrm{~h}$, the RAW 264.7 cells were pretreated with various concentrations of polyphenol colloidal particles for $2 \mathrm{~h}$, then the cells were stimulated with PMA $\left(500 \mu \mathrm{g} \mathrm{mL}^{-1}\right)$ for $1 \mathrm{~h}$. Then culture medium was replaced with serum-free medium containing DCFH-DA $(20 \mu \mathrm{mol} \mathrm{L}-1)$ for a 30 min treatment. Then the cells were collected and the intracellular ROS level was determined on a flow cytometer by measuring the fluorescence $(\mathrm{Ex}=488, \mathrm{Em}=525)$. Each group was carried out in triplet and ordinary one-way analysis of variance (ANOVA) is used for statistical analysis, ${ }^{*} \mathrm{p}<0.05 ;{ }^{*} \mathrm{p}<0.01$; and $* * * \mathrm{p}<0.005$.

Polyphenol contents of tea infusion and residual formaldehyde. An Agilent 1260 HPLC system equipped with a UV-Vis detector and an XDB-C18 column $(5 \mu \mathrm{m}, 4.6 \times 150 \mathrm{~mm})$ was used to the measurement. For determining the polyphenol contents of tea infusion, an isocratic elution (methanol: water: ethyl acetate $=13: 84: 3$ ) was used to separate different contents. The mobile phase was adjusted to $\mathrm{pH} 2.30$ with phosphoric acid. The signal was detected at $280 \mathrm{~nm}$, and the oven temperature was $30^{\circ} \mathrm{C}$.Certified reference materials were used to make calibration curves. Flow rate was $1.7 \mathrm{~mL} / \mathrm{min}$. Injection volume was $20 \mu \mathrm{L}$. For determining the residual formaldehyde, polyphenol colloidal particles were centrifuged and re-dispersed in acetonitrile $\left(6 \mathrm{~mL}, 10 \mathrm{mg} \mathrm{mL}^{-1}\right)$, then the solution was treated with ultrasonic for $30 \mathrm{~min}$ to extract the residual formaldehyde. The supernatant was collected by centrifugation $\left(10,000 \mathrm{RCF} \times \mathrm{g}, 10 \mathrm{~min}, 4^{\circ} \mathrm{C}\right)$ and filtration $(0.22 \mu \mathrm{m})$. The $2,4-\mathrm{DNPH}$ solution $(2.5$ $\mathrm{mL}, 3.0 \mathrm{mg} \mathrm{mL}^{-1}, 1 \%$ phosphoric acid) was added into the filtrate $(5 \mathrm{~mL})$ and incubated at $40^{\circ} \mathrm{C}$ for 60 $\min$. The mobile phase was composed of methanol/water $(65: 35)$. The temperature was set as $40^{\circ} \mathrm{C}$. Injection volume was $20 \mu \mathrm{L}$. Flow rate was $1.0 \mathrm{~mL} / \mathrm{min}$. The signal was detected at $355 \mathrm{~nm}$. The certified reference formaldehyde solution used to make a calibration curve. 


\section{Supplementary Figures and Tables.}

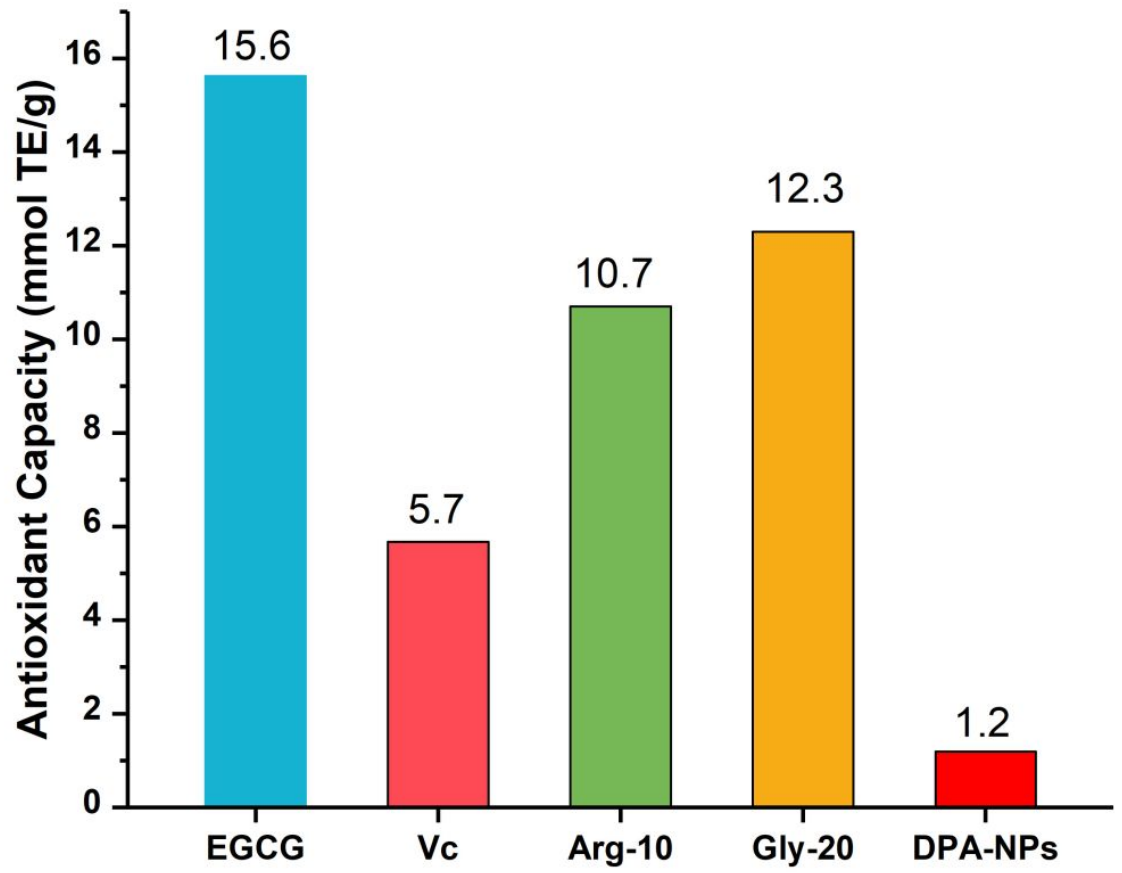

Figure S1. Quantitative antioxidant capacity of EGCG, Vc, Arg-10, Gly-20 and polydopamine nanoparticles (DPA-NPs) in scavenging ABTS radicals.
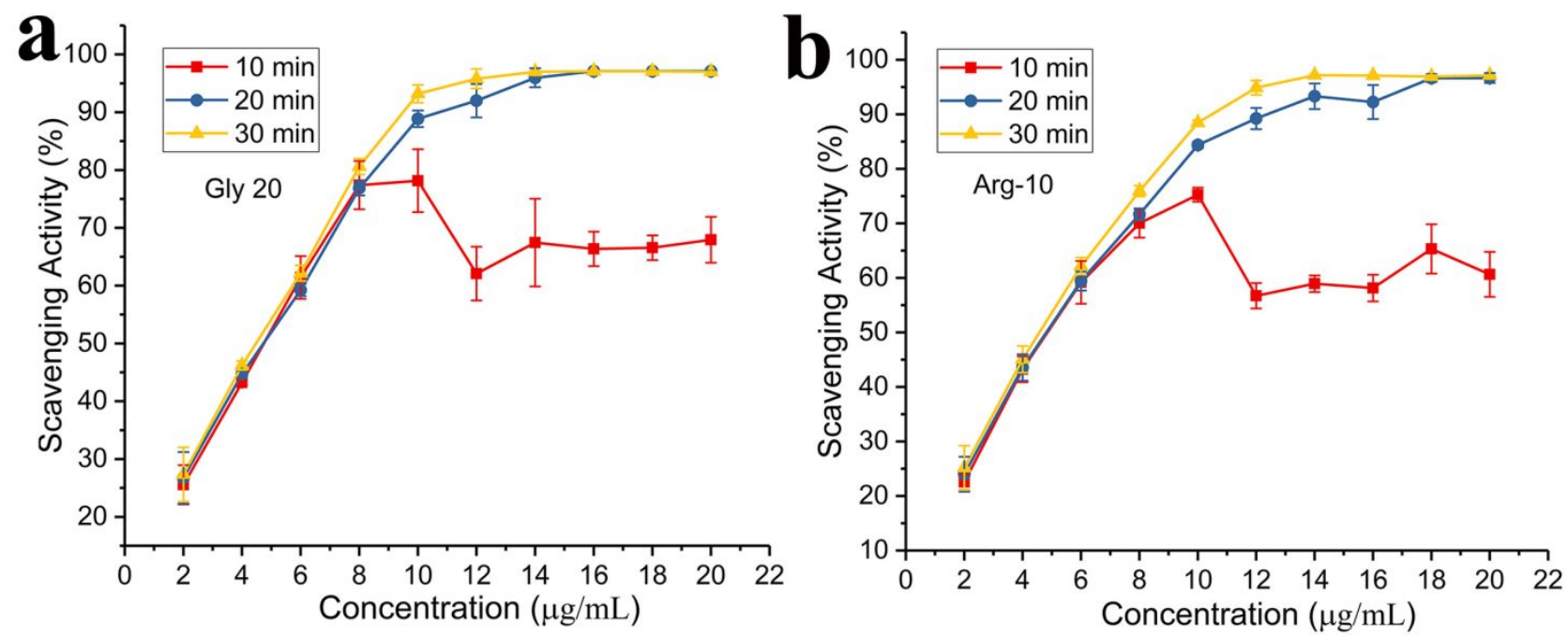

Figure S2. ABTS radical scavenging activity of (a) Gly-20 and (b) Arg-10 measured at different evaluation periods $(10,20,30 \mathrm{~min})$. According to the results, the optimum evaluation period of the ABTS radical scavenging assay is $30 \mathrm{~min}$. 


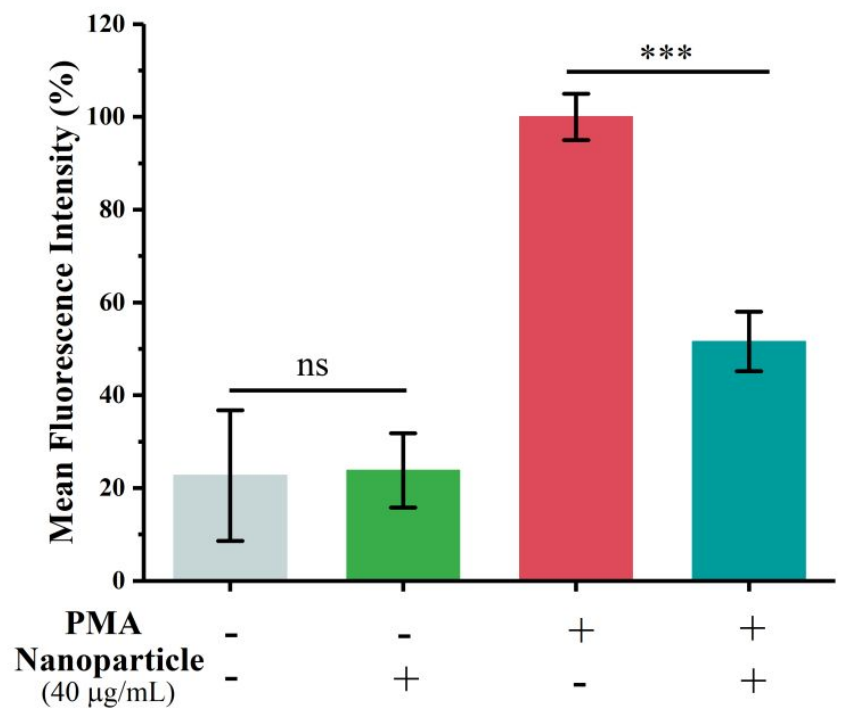

Figure S3. Reactive oxygen/nitrogen species level of Raw 264.7 (with or without PMA stimulation) pre-treated with $40 \mu \mathrm{g} \mathrm{mL}^{-1}$ of Gly-20. ( $\mathrm{n}=3$, mean \pm s.d.). Ordinary one-way analysis of variance (ANOVA) is used for statistical analysis, ${ }^{*} \mathrm{p}<0.05 ; * * \mathrm{p}<0.01$; and $* * * \mathrm{p}<0.005$.
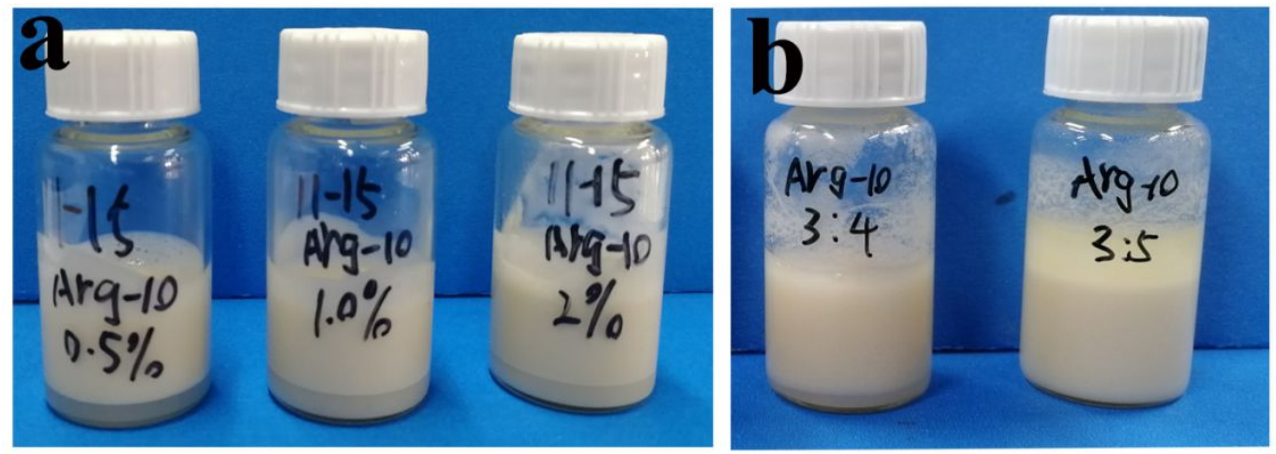

Figure S4. (a) Emulsions prepared with Arg-10 (without rhodamine 6G staining) at the concontration of 5.0, 10.0 and $20.0 \mathrm{mg} \mathrm{mL}^{-1}$ (water:oil =1:1). (b) Emulsions prepared with different volume ratio of water to oil $(3: 4$ and $3: 5)$. 

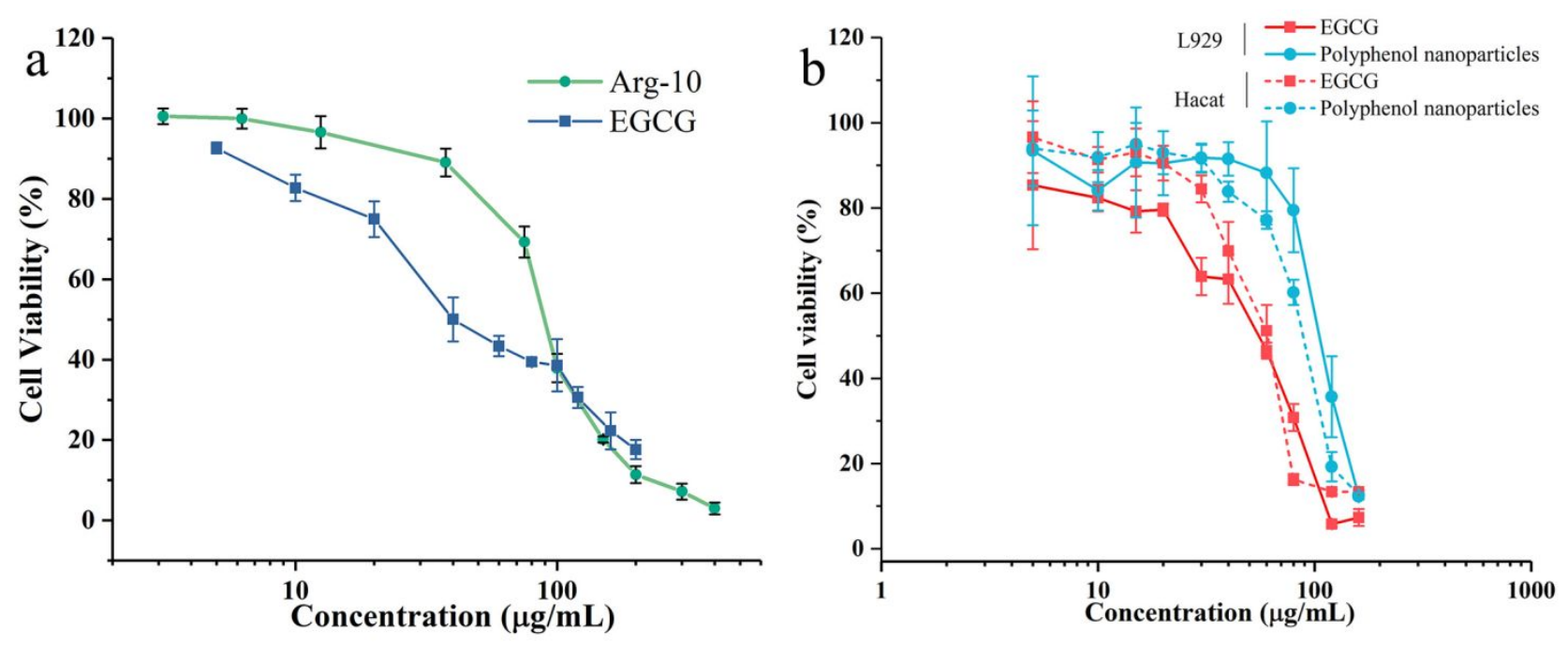

Figure S5. Cytotoxicity assays of (a) 4T1, (b) L929 and Hacat cells treated with EGCG or polyphenol nanoparticles for $24 \mathrm{~h}$.

Table S1. Element analysis of Arg-10 and Gly-20. $(n=3$, mean \pm s.d. $)$

\begin{tabular}{|c|c|c|c|c|c|}
\hline \multicolumn{5}{|c|}{ Elemental analysis } & \multicolumn{2}{c|}{ Mass fraction of amino acid } \\
\hline Name & $\mathrm{N}(\%)$ & $\mathrm{C}(\%)$ & $\mathrm{H}(\%)$ & $\begin{array}{c}\text { Theoretical value } \\
(\%)\end{array}$ & $\begin{array}{c}\text { Detection value } \\
(\%)\end{array}$ \\
\hline Arg-10 & $4.97 \pm 0.05$ & $51.58 \pm 0.03$ & $5.42 \pm 0.02$ & 10.1 & $15.51 \pm 0.16$ \\
\hline Gly-20 & $4.35 \pm 0.05$ & $52.22 \pm 0.04$ & $5.42 \pm 0.01$ & 18.6 & $23.30 \pm 0.27$ \\
\hline
\end{tabular}
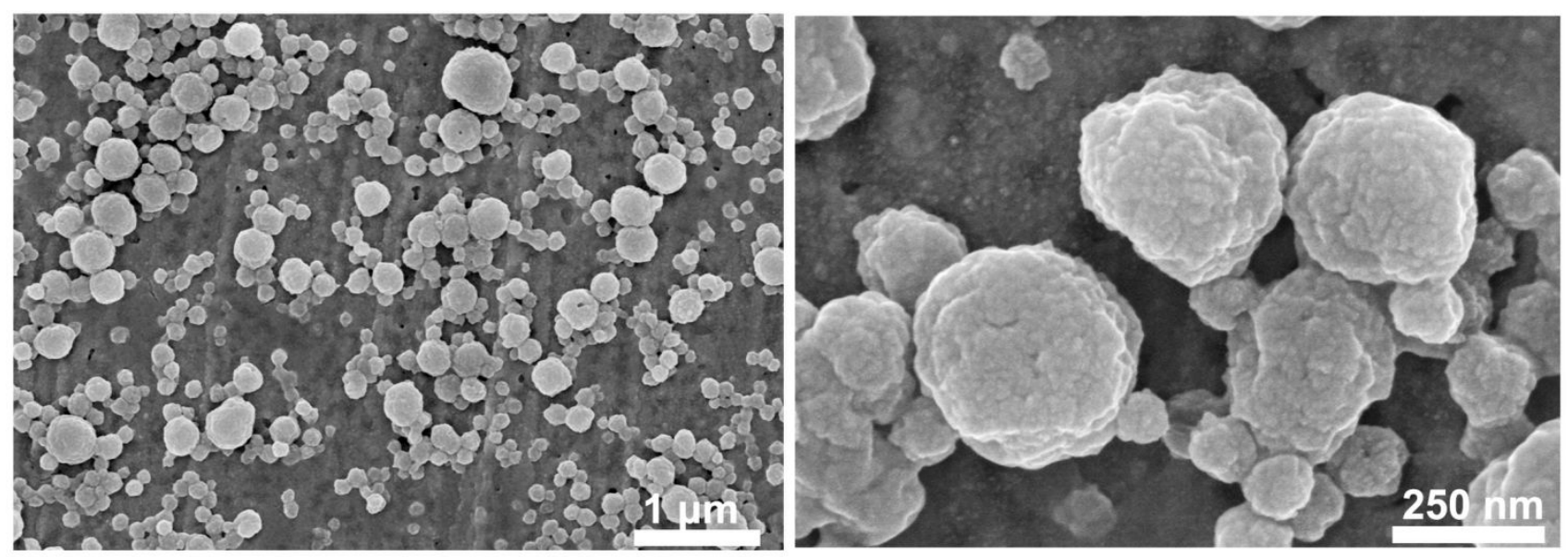

Figure S6. SEM images of polyphenol nanoparticles prepared from the black tea with the additon of formaldehyde and glycine. The particles with porous surface are also visible in the SEM images. 


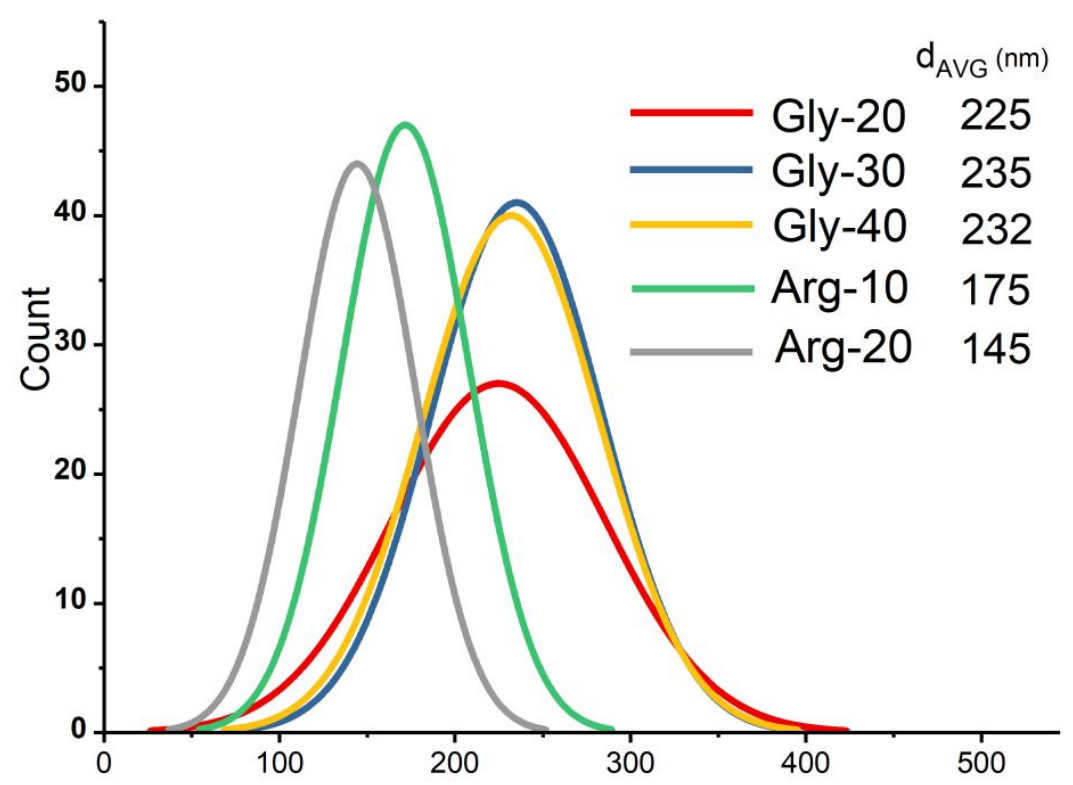

Figure S7. Size distribution (calculated from the SEM images) of different nanoparticles obtained from tea infusions. $n=200$.

Table S2 Recovery rate of polyphenols in Gly-20 groups calculated from HPLC chromatography.

\begin{tabular}{lccc}
\hline \multirow{2}{*}{ Component } & \multicolumn{2}{c}{ Concentration } & $\left(\mathrm{mg} \mathrm{L}^{-1}\right)$ \\
& Tea infusion & Supernatant & Recovery rate (\%) \\
\hline (1) gallic acid & 133.9 & 114.0 & 14.9 \\
(2) caffeine & 430.2 & 336.0 & 21.9 \\
(3) epigallocatechin & 680.8 & 334.8 & 50.8 \\
(4) catechin & 98.7 & 7.7 & 92.2 \\
(5) epicatechin & 148.9 & 145.1 & 2.6 \\
(6) epigallocatechin gallate & 590.2 & 4.2 & 99.3 \\
(7) gallocatechin gallate & 150.2 & 10.5 & 93.0 \\
(8) epicatechin gallate & 220.3 & 9.3 & 98.7 \\
\hline
\end{tabular}



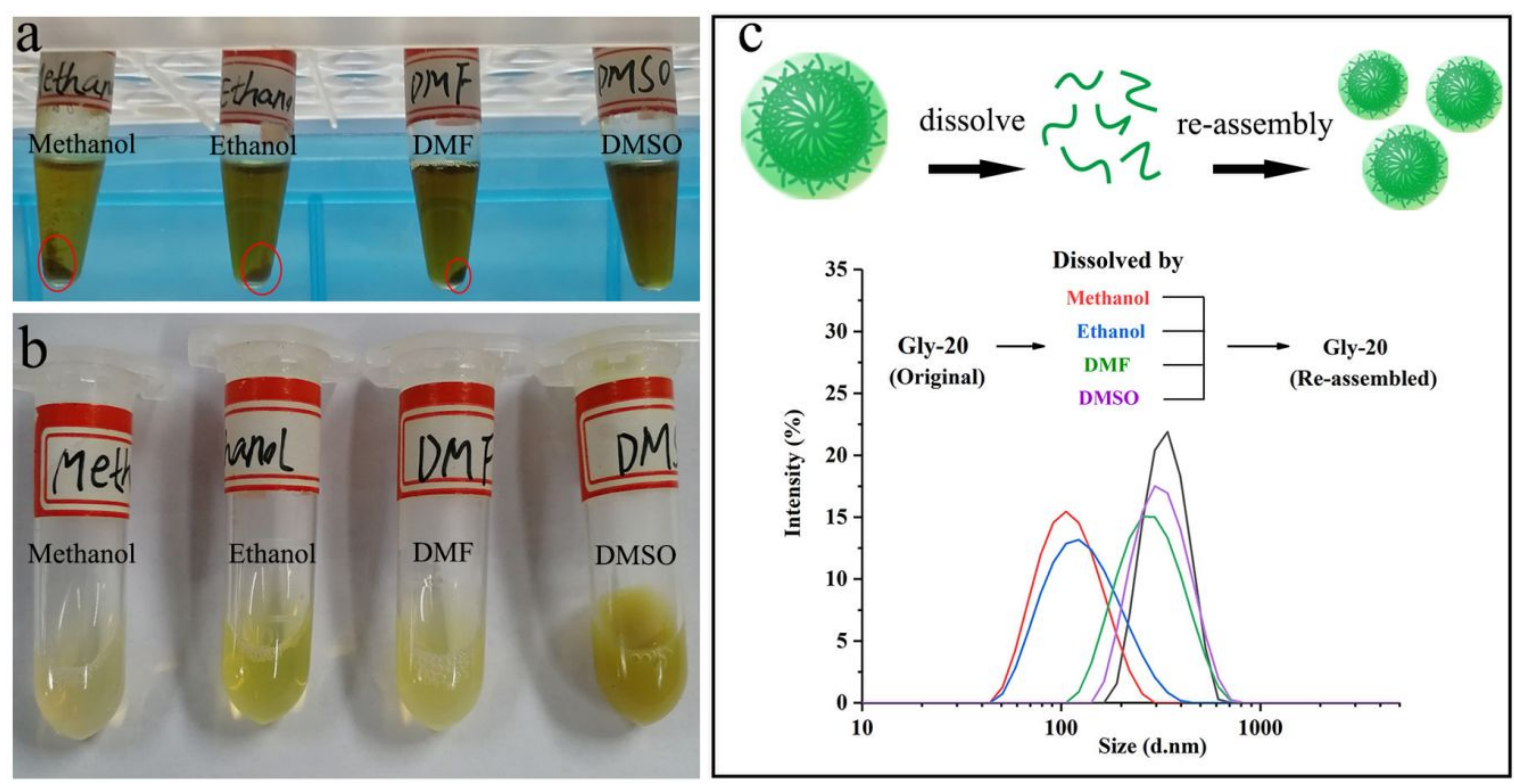

Figure S8. (a) The recovered polyphenol nanoparticles (Gly-20, $5 \mathrm{mg}$, collected by centrifugation) were dissolved in $400 \mu \mathrm{L}$ of different solvents (partially dissolved in methanol, ethanol, DMF and totally dissolved in DMSO). (b) The polyphenol nanoparticles with smaller size were obtained by adding the clear supernatant into water. (c) Scheme illustration of the disassembly in organic solvents and re-assembly process in water of the polyphenol nanoparticles. DLS results indicated the smaller size of the re-assembled nanoparticles. 